\title{
O envelhecimento na atualidade: uma controvertida produção coletiva
}

\section{The aging in current: a controversy collective production}

\author{
1 Julio Cesar de Almeida Nobre julio.nobre@foa.org.br \\ 2 Ivanete da Rosa Silva de Oliveira \\ 3 Thabata Braga Mendes \\ 4 Arlene Assis de Oliveira \\ 5 Liz Rodrigues de Souza \\ 6 Renata Rodrigues Silva
}

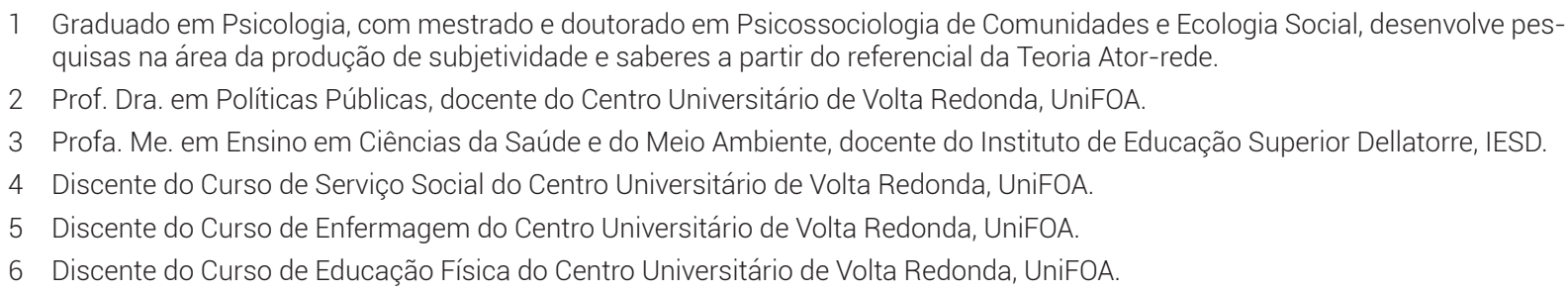

\section{Resumo}

Atualmente, inúmeros são os argumentos acerca da velhice, estando estes atrelados e relacionados a interesses diversos. Alguns apontam para uma realidade na qual o humano seria produzido como um objeto, sendo valorizado somente pela sua produtividade. Outros argumentam pelo viés da melhoria da qualidade de vida, visando manter o indivíduo jovem e ativo por muito mais tempo ou se amparam em propostas acerca da necessidade de lutar por esse segmento social, considerado como fragilizado. Enfim, diversas são as abordagens que se produzem frente à questão da velhice. 0 presente estudo tem por objetivo realizar uma cartografia acerca da produção do envelhecimento na atualidade, articulando-a aos referenciais da Teoria Ator-rede - TAR e, desse modo, concebendo-a como um efeito de instáveis redes em ação, um circuito de mediadores. Tal cartografia configura-se como uma descrição dos circuitos produtivos de fronteiras espaciais delimitadoras da realidade do envelhecimento na atualidade, concepção permeada por intensas controvérsias. Busca-se evidenciar redes coletivas e heterogêneas de mediadores/mediações a constituir grupos e antigrupos, circulações e resistências. Tais mediações, ao tecerem realidades acerca do envelhecimento, seguem imbricadas com uma multiplicidade de vozes que são trazidas a argumentar. Temos aqui uma realidade, na qual o envelhecimento se produz em meio à mídia, instituições financeiras, agências de turismo, política, biologia, acadêmicos, dentre outros.

\section{Palavras-chave}

Teoria Ator-rede; envelhecimento; cartografia.

\begin{abstract}
Nowadays, there are innumerable arguments about old age, these being linked and related to diverse interests. Some point to a reality in which the human would be produced as an object, being valued only for its productivity. Others argue for the bias of improving the quality of life, aiming to keep the individual young and active for much longer, or to support proposals about the need to fight for this social segment, considered as fragile. In short, there are several approaches to the question of old age. The present study aims to map the aging production in the present time, articulating it to the references of the Theory-actor-network and thus, conceiving it as an effect of unstable networks in action, a circuit of mediators. Such cartography is a description of the productive circuits of space boundaries delimiting the reality of aging today, a concept permeated by intense controversy. It seeks to evidence collective and heterogeneous networks of mediators / mediations to constitute groups and anti-groups, circulations and resistances. Such mediations, by making realities about aging, are interwoven with a multiplicity of voices that are brought up to argue. We have a reality here, in which aging occurs in the midst of the media, financial institutions, tourism agencies, politics, biology, academics, among others.
\end{abstract}

\section{Keywords}

Actor-network theory; aging; cartography. 


\section{INTRODUÇÃO}

Nos dias atuais, as discussões em torno de temáticas que são produzidas por relações preconceituosas que depreciam o ser humano vêm sendo assumidas por debates no âmbito acadêmico. Desse modo, tem-se percebido que rótulos e estigmas sociais articulados à concepção de velhice vêm circulando, naturalizando e, inclusive, contribuindo com interesses diversos.

Essa perspectiva foi apontada pelos estudos de Eneida Gonçalves de Macedo Haddad, quando investigou sobre a multiplicidade de mediadores que contribuem para a produção do discurso sobre a velhice. A autora argumenta que a produção dos valores que estão atrelados a esse artefato, são (re) arranjados por determinações que estão diretamente articuladas a múltiplos interesses capitalistas que convergem para a valorização do homem apenas como objeto de produtividade, fragmentando a sua existência e, consequentemente, superestimando a fase do trabalho e subestimando a fase não produtiva laboral.

\footnotetext{
A ideologia da velhice é elemento fundamental à reprodução das relações capitalistas na medida em que a produção das relações capitalistas implica a reprodução de ideias, valores, princípios e doutrinas, o conjunto de representações sobre a etapa final da vida humana é organizado segundo as determinações básicas do modo capitalista de produção (HADDAD, 1986, p. 16).
}

Tais argumentos acabam por nos conduzir a diferentes mediadores que vêm concebendo o enveIhecimento sob duas correntes, porém ambas imbricadas com valores capitalistas. A primeira corrente se (re)organiza pelo viés da melhoria da qualidade de vida. Essa corrente é tecida pelo anúncio de propostas que enaltecem práticas de como se manter jovem e ativo por muito mais tempo. Destacam-se, nessa perspectiva, mediadores, tais como a indústria cosmética e farmacológica, os programas de promoção da saúde e integração social, a participação em grupos de atividade física que prometem, não só a manutenção dos aspectos orgânicos e biológicos, mas também a elevação da autoestima, que reflete na qualidade e predisposição para a vida. Essa corrente, entretanto, se projeta principalmente pela concepção da velhice em oposição à jovialidade, portanto, muitas vezes, se produz pela negação do processo de envelhecer.

Uma segunda corrente ampara-se em propostas acerca da necessidade de lutar por esse segmento social que é considerado como escamoteado e fragilizado. Articulados a essa concepção estão aqueles que apreendem a velhice sob os aspectos do declínio gradual das capacidades funcionais e cognitivas. Nessa perspectiva, velhice é produzida como sinônimo de doenças, isolamento, abandono e improdutividade, articulando-a com aspectos como a idade cronológica e às relações do trabalho. Imbricada a essa ideia, temos, ainda, a aposentadoria como marco do envelhecimento, que remete e situa o idoso à condição de inativo. Em sintonia com tais afirmações, temos o argumento de Júlio Assis Simões (1998), que aponta que a velhice, relegada ao descaso histórico-social, tem sua existência comprovada somente pelo número estatístico que, geralmente, se articula com a política que se promove por meio do idoso.

Salienta-se, entretanto, que ambas correntes parecem atuar na produção da velhice como uma categoria específica de investimento e arrecadação, subsidiando a criação de projetos redentores e assistencialistas e/ou que se apresentam como verdadeiros tônicos rejuvenescedores na atenuação do processo de envelhecimento. Desse modo, na atualidade, diferenciadas abordagens se produzem frente à questão da velhice, evidenciando novos modos de envelhecer e, concomitantemente, muitas vezes, instigam interesses que percebem o idoso como um objeto que apresenta condições de consumir, poupar ou investir, sendo, então, cobiçado pela mídia, pelas instituições financeiras, agências de turismo e, até mesmo, candidatos a cargos políticos. 
Diante do exposto, o presente estudo parte da premissa que o advento do aumento da longevidade vem se imbricando com mediadores diversos que (co)produzem a concepção de velhice na atualidade. Não restrita a fronteiras puramente fisiológicas, psicológicas e/ou econômicas, o envelhecimento produz-se em uma constante circulação a envolver mediadores de diferentes dimensões. Assim, pretende-se rastrear e descrever a produção do envelhecimento por meio dos controvertidos argumentos de múltiplos porta-vozes, mediações de ordens diversas.

Nesse sentido, áreas da ciência, como a gerontologia e a geriatria, têm importância significativa em meio a tal coletivo turbulento, visto que se dedicam ao estudo de questões sobre o envelhecimento em diversos prismas. Os argumentos científicos dessas áreas do saber, então, parecem se configurar como importantes portas de entrada para uma rede coletiva que, em conjunto com o final da vida humana, o Estado, instituições sociais, mídia, fármacos, o próprio idoso, dentre outros, fazem circular aquilo que entendemos por envelhecimento.

A Gerontologia e a Geriatria apresentam-se como as principais instâncias produtoras da ideologia da velhice. Aparecem como entidades autônomas, enquanto produtoras de um saber intelectual elaborado pelos aparentemente autônomos pensadores da velhice (HADDAD, 1986, p. 33).

Temos aqui mais um embate a demonstrar o quanto tal coletivo a produzir o envelhecimento é bastante controvertido. Se por um lado dispomos dos argumentos nativos da geriatria e gerontologia, por outro encontramos os argumentos de Haddad, em que tais saberes são traduzidos como autoridades que reivindicam projetos em nome do idoso, ignorando diversos fatores articulados ao processo de surgimento da problemática da velhice. Desse modo, apropriando-se da velhice como objeto de estudo, essas áreas de conhecimento conceberiam o homem, desde seu nascimento, em fases estanques, fragmentado.

O argumento crítico de Haddad parece sintonizar com Simone de Beauvoir (1990, p.10), quando ela defende que o homem, no decorrer do seu processo evolutivo, chega à velhice sem perceber que ela já o habitava desde sua concepção "Antes de desabar sobre nós, a velhice é coisa que só diz respeito aos outros. Pode-se assim compreender que a sociedade consiga evitar que enxerguemos semelhantes nossos nos velhos" (BEAUVOIR, 1990, p. 12). A autora ainda sinaliza a necessidade de que os homens permaneçam homens, quando avançados em anos.

Desse modo, neste artigo, procuramos analisar a concepção de envelhecimento na atualidade, articulando-a aos referenciais da Teoria Ator-rede - TAR, concebendo-a como um efeito de instáveis redes em ação, um circuito de mediadores. Para atingir tal objetivo, focalizamos no desenvolvimento de uma cartografia descritiva da produção das fronteiras daquilo que se entende por envelhecimento na atualidade, concepção permeada por intensas controvérsias. Nessa perspectiva, buscou-se evidenciar redes heterogêneas de mediadores/mediações a produzir tais fronteiras e principais porta-vozes a formar grupos e antigrupos, circulações e resistências.

Diante do cenário apresentado, entendemos que a Teoria Ator-Rede - TAR pode ser caracterizada como um importante aliado na análise da produção daquilo que entendemos por envelhecimento na atualidade. A TAR configura-se como um relevante referencial teórico-metodológico na abordagem de instáveis coletivos, visto que, segundo a principal expressão dessa teoria, o antropólogo francês Bruno Latour (2008), as controvérsias devem ser concebidas como momentos de singular importância na abordagem dos coletivos. Quando estamos imersos na turbulência, situados em lutas e formações de grupos e antigrupos, mediadores dispostos em oposição, podemos perceber a riqueza das existências em formação, a "cozinha dos fatos" em ação, na justa medida das múltiplas mediações (LATOUR, 2000). Por mediador, entende-se aquele que detém a capacidade do desvio. Tal mediador pode ser tanto da ordem dos humanos quanto dos não humanos, visto que não apenas os humanos possuem 
a possibilidade da ação. Os objetos técnicos não estão aprisionados nas intenções iniciais humanas. Eles detêm a capacidade de resistência a tais intenções (LATOUR, 1994, 1996).

Sendo assim, de mediador em mediador, uma realidade vai sendo tecida. Tal tessitura pode circular dentro de um regime de caixa preta, como uma circulação sem maiores controvérsias. Entendemos que as atuais controvérsias acerca do envelhecimento podem ser entendidas como um momento de instabilidade nessas circulações. Uma abertura de caixa-preta, mais precisamente, uma caixa-cinza: "quando uma técnica ainda não está completamente estabelecida como caixa-preta, falamos de caixa cinza (Latour) ou caixa translúcida (Jordan e Lynch)" (VINCK apud NOBRE; PEDRO, 2007, p. 228).

Desse modo, propomo-nos a realização de uma cartografia descritiva das controvérsias a envolver a produção do envelhecimento na atualidade. Um rastreamento de mediações que possibilite a elaboração de um relato plano, sem uma dimensão de profundidade. Uma descrição que não se queira una e verdadeira. A produção de um relato/mediador que seja potente, devido à multiplicidade de vozes que são trazidas a argumentar.

\section{ENVELHECIMENTO NA ATUALIDADE: DIFERENTES PORTA-VOZES}

O aumento de velhos no índice populacional era sinônimo de comemorações, devido aos progressos e ao estímulo à longevidade, até meados do Século XIX. Com o passar do tempo, um novo cenário populacional foi se produzindo, alterando a pirâmide etária, principalmente provocada pela redução da taxa de natalidade e de mortalidade de idosos. Dentre fatores que impactaram nessa realidade, podemos destacar os avanços tecnológicos e aqueles atrelados aos direitos básicos do cidadão, no que diz respeito a um maior investimento e a uma maior atenção à saúde. Esses avanços, que incluíam, além do cuidado, a prevenção e a promoção da saúde, contribuíram para o aumento da expectativa de vida (ALVES JUNIOR, 2009). Goldman (2009) reforça essa assertiva e afirma que, a partir do século XX, passou-se a se considerar outros determinantes que contribuem para o aumento da expectativa de vida, tais como as melhorias no saneamento básico e a questão ambiental.

Na mesma proporção que se ampliava a expectativa de vida, também se produzia diferentes olhares para esse setor/grupo na sociedade, assumindo-se perspectivas que convergiam para uma velhice que necessitava de cuidados e maior atenção, por ser considerada fragilizada - ou pela necessidade de se manter o indivíduo articulado à sociedade produtiva por maior tempo possível.

Nos países onde a política do bem-estar social foi instaurada, idosos passaram a usufruir de uma qualidade de vida maior, mesmo sendo do ponto de vista material. Esse aspecto colaborou para a produção de posturas diferenciadas diante do envelhecimento, sendo que, em alguns países, onde há maior expectativa de vida, há também uma participação expressiva de idosos na sociedade.

Para o Instituto Brasileiro de Geografia e Estatística - IBGE (2010), o crescimento da população de idosos em números absolutos e relativos é um fenômeno mundial e está ocorrendo em um nível sem precedentes. Em 1950, eram cerca de 204 milhões de idosos no mundo e, já em 1998, quase cinco décadas depois, esse contingente alcançava 579 milhões de pessoas, um crescimento de quase oito milhões de pessoas idosas por ano. As projeções indicam que, em 2050, a população idosa será de 1.900 milhões de pessoas, montante equivalente à população infantil de 0 a 14 anos de idade.

Assim como em outros países do mundo, o Brasil tem acompanhado essa tendência de transição demográfica. As taxas de fecundidade ou natalidade têm reduzido significativamente e os avanços na qualidade de vida, saúde e educação têm proporcionado uma expectativa de vida maior, fazendo com 
que a população brasileira se torne mais velha. 0 envelhecimento, no Brasil, tem ainda características próprias, como o fato de as mulheres possuírem uma longevidade maior que os homens e a redução significativa da população idosa nas áreas rurais, devido à maior qualidade de serviços especializados de saúde, saneamento e a outros facilitadores do cotidiano nos grandes centros urbanos (IBGE, 2010). Importante salientar que a tendência parece ser a de um envelhecimento cada vez mais rápido da população brasileira. A mudança significativa na faixa etária média da população como um todo e o aumento na população velha, prevista para o período de 2025 e 2050, impacta e instabiliza diretamente alguns parâmetros sociais, como aqueles que estão articulados à quantidade de cidadãos em idade ativa que, em decorrência do aumento da expectativa de vida, tende a diminuir, ocasionando um impacto na economia do país.

Goldman argumenta que essa visão contribui para a produção de uma velhice articulada às premissas do capital, que se produz pela tendência de transformar pessoas em mercadorias, já que são essenciais para "gerar dinheiro" e, nessa condição, os velhos seriam considerados descartáveis, por não terem o mesmo potencial como mão de obra para oferecer, quando comparado aos jovens (GOLDMAN, 2009, p.14). Essa perspectiva motiva autores, como Alves Junior (2009), a afirmarem que a transição demográfica pautada no alargamento da população idosa, em detrimento dos nascimentos, traz consigo um problema social, pois afeta os países socialmente e os enfraquece economicamente.

Alguns argumentos parecem traduzir o envelhecimento como tendo sido, partir do século XX, articulado a uma condição de classe excluída da sociedade, sendo o velho discriminado, desrespeitado e, muitas vezes, não tendo seus direitos garantidos enquanto cidadão. Simões (1998) defende que a complexidade da definição de políticas sociais, em relação à velhice, manifesta-se de imediato por meio da denominação do objeto estudado, ao qual vem sendo atribuído diferentes qualificações, como a de terceira idade, que contribui para a produção da negação do fenômeno relacionado ao sujeito que envelhece. 0 autor considera que tal terminologia, terceira idade, tenha seu princípio cronológico articulado aos sistemas legislativos de aposentadoria, que se contrapunha ao emprego lucrativo, cuja faixa varia de 60 a 65 anos. (FUSTIONONI, 1982, p.8 apud SIMÕES, 1998, p. 13)

[...] uma diminuição de renda e perda do status social o que vai demandar adaptação a um novo padrão de comportamento ou a um novo processo de socialização com o ensino e a aprendizagem de funções sociais. 0 aposentado tende a diminuir o nível de contatos sociais rompendo, muitas vezes, o elo de ligação [sic] com o mundo do trabalho. Ocorre com frequência a perda do cônjuge o que vai requerer a assunção do papel de viúvo, que pode ser acrescido de outro papel, o de doente, visto que as doenças (reais ou fictícias) fazem parte do cotidiano dessa população (SIMÕES, 1998, p. 18).

Articulado a esses argumentos, temos traduções que propalam que o idoso, para não romper com a rotina do ambiente laboral, deve participar de grupos como aqueles pertencentes ao campo religioso, culturais, esportivo, etc. 0 "manter-se ativo" é considerado como fórmula para uma velhice agradável e saudável (SIMÕES, 1998).

Os defensores dessa teoria entendem o processo de desengajamento como necessário e funcional tanto para o indivíduo, que aprende a se preparar para a morte, quanto para a sociedade na medida em que o desaparecimento de uma pessoa desengajada não implicará em perdas sociais. Sob a lógica da teoria em tela, o caráter descartável do idoso é funcional à sociedade de consumo, reproduzindo, sem máscaras, as mazelas do capitalismo (SIMÕES, 1998, p. 19).

Vale ressaltar que, por outro lado, de modo articulado a valores econômicos, a velhice também parece se produzir como aquela que pode adquirir serviços e bens ofertados para a população idosa tais como, viagens, atendimento geriátrico especializado, atividade física, produtos farmacêuticos e de estética que prometem manter a "juventude eterna" etc. Desse modo, pode-se observar a produção de 
um idoso feliz, um tanto rejuvenescido, com fontes de renda e outros bens, caracterizando uma velhice apta para consumo ${ }^{7}$.

Ao considerarem o envelhecimento como perda de capacidade física e, na maioria das vezes, entendido como apenas um problema médico, Neri e Freire (2000), traduzem o envelhecimento como ainda estando ligado à deterioração do corpo, ao declínio e à incapacidade. "Na base da rejeição ou da exaltação acrítica da velhice, existe uma forte associação entre esse evento do ciclo vital com a morte, a doença, o afastamento e a dependência" (NERI \& FREIRE, 2000, p. 8). A segunda metade do século XIX começou a tratar a velhice como uma etapa da vida caracterizada pela decadência física e ausência de papéis sociais. Para Debert (1999), o avanço da idade dar-se-ia como um processo contínuo de perdas e de dependência, que daria uma identidade de falta de condições aos idosos e seria responsável por um conjunto de imagens negativas associadas à velhice.

\begin{abstract}
As associações negativas relacionadas à velhice atravessaram os séculos e, ainda hoje, mesmo com tantos recursos para prevenir doenças e retardá-la, é temida por muitas pessoas e vista como uma etapa detestável. A célebre frase de uma artista brasileira idosa famosa, "o envelhecimento é a prova de que o inferno existe" (grifo nosso), demonstra o quanto a velhice é uma experiência individual que pode ser vivenciada de forma positiva ou negativa, em consonância com a história de vida da pessoa e da representação de velhice que está enraizada na sociedade em que vive. Assim, pode-se inferir que não importa a quantidade de anos que o indivíduo tem, mas sim, o que ele fez com os anos vividos, e como a sociedade trata alguém com aquela idade (SCHNEIDER; IRIGARAY, 2008, p.03).
\end{abstract}

Dessa forma, a velhice possui uma produção coletiva com princípios contraditórios e bastante turbulenta. Para Schneider e Irigaray (2008), na atualidade, ao mesmo tempo em que a sociedade potencializa a longevidade, ela nega aos velhos valor positivo e importância social. Vive-se em uma realidade voltada para o consumo, na qual apenas o novo pode ser valorizado, pois, sem tal pressuposto, teríamos resistência à produção e acumulação de capital. Nesse cenário, o velho passa a ser produzido como ultrapassado, descartado ou fora de moda. Pacheco (2005) toma, como exemplo, o fenômeno dos aparelhos celulares:

\begin{abstract}
em poucos anos, eles se modificaram centenas de vezes. Desenhos modernos, bonitos e funcionais são criados para que as pessoas pareçam antenadas, jovens e bem-sucedidas. 0 medo da transformação que surge com a velhice assemelha-se um pouco ao fenômeno dos celulares. Tem-se medo de envelhecer como se tem receio de ser ridicularizado ao usar o aparelho antigo de dez anos, como os tijolões dos 'tiozinhos'. O ser humano envelhecido é-nos apresentado, pela ideologia dominante, como o aparelho ultrapassado. Fala, mas ninguém quer! (PACHECO; 2005, p. 65).
\end{abstract}

Considerando a valorização da juventude, beleza, autonomia, independência e capacidade de produtividade, "ser velho" parece assumir uma conotação negativa, formalizado como a perda desses atributos tão valorizados. Para Jones (2006), o significado relacionado às pessoas mais velhas é amplamente negativo, embora não seja exclusivamente assim. 0 autor argumenta que os estereótipos negativos são atribuídos principalmente pelos próprios idosos, que não se reconhecem como tal e falam da categoria "velho" como se não fizessem parte dela. É comum que a maioria das pessoas mais velhas resista a ser chamada de velha. Segundo Ferreira (2000), a palavra "velho" significa muito idoso, antigo, gasto pelo tempo, experimentado, veterano, que há muito tempo exerce uma profissão ou tem certa qualidade, desusado, obsoleto.

Resistindo a tal produção da velhice, temos Gibson (2000), autor que argumenta sobre o quanto atitudes preconceituosas estão também incorporados na linguagem e, assim, levarão muitos anos para

7 Outros mediadores, por sua vez, parecem se apoiar nas políticas sociais voltadas para esse segmento populacional, dentre as quais estão aquelas que estabelecem regras para a aposentadoria, para pensão por morte para viúva ou viúvo, cálculo do benefício, reajuste dos benefícios vinculados ao salário mínimo, até o salário de setembro de 1991, e pelo INPC (Índice Nacional de Preço ao Consumidor) após esse período. Destaca-se, também, a lei nº 8842 de 4 de janeiro de 1994, que dispôs sobre a política nacional do idoso (SIMÕES, 1998, p. 33-34). 
mudarem. Para ele, a palavra velho não significa decrepitude, desgaste, fora de moda, mas simplesmente se refere ao número de anos que a pessoa viveu.

Temos, portanto, uma atualidade em que o envelhecimento parece possuir múltiplos processos produtivos, muitos deles contraditórios entre si. Se por um lado, por exemplo, encontram-se argumentos que parecem produzir um idoso consumidor, produtivo e potente, estes convivem com traduções que dão contornos ao velho articulados à decrepitude e fragilidade. Sigamos adiante.

\section{O REFERENCIAL DA TEORIA ATOR-REDE - TAR}

A Teoria Ator-Rede - TAR, referencial teórico-metodológico utilizado na presente pesquisa, não concebe a realidade como uma dimensão espacial, fixa e imóvel. O foco aqui incide na produção dessa realidade como um processo de constante redefinição, uma rede de fluxos. Tendo Bruno Latour como seu principal expoente, tal referencial atenta-se para as práticas cotidianas a abarcar sociedade, tecnologia e ciência. Desse modo, tem-se uma produção da existência por meio de circuitos, redes, nos quais a ação de mediadores humanos e não humanos é fundamental. Desse modo, segundo Nobre e Pedro (2010, p. 48) "tal emaranhado nos possibilita pensar não mais em termos de unidade, mas a partir de um dinamismo processual e sempre constante de associações".

A partir da TAR, diferentemente de uma ideia macro, rígida e sólida de sociedade, concebemos o social como o próprio fluxo. A teoria entende que um social enrijecido não sabe lidar com instabilidades. Tal modelo de fluxos busca trazer potência ao trabalho dos mediadores e o modo como eles agem para produzir a realidade. Latour (apud Nobre e Pedro, 2010), ao não se utilizar do termo ator, muito impregnado de humanidade, denomina os mediadores como actantes (LATOUR, 2001), visto que eles englobam tanto humanos quanto não humanos. Os mediadores, entendidos como nós em uma rede, possuidores da capacidade de desvio, de levar tal rede adiante, tecem novos espaços em um contínuo processo de redefinição. De mediação em mediação, o fluxo vai se dando em tempo real. Temos um coletivo, gerando assim, uma realidade, a atualidade.

Sendo a realidade sempre uma rede em ação, quando se delineia como um fato, é possível rastreá-lo em seu processo produtivo, como um efeito em cadeia de transformações, de processos de mediação (NOBRE; PEDRO, 2010). Tendo em vista, portanto, que a realidade se produz de amarração em amarração, construída em camadas e sem um ponto fixo que se preste como fundamento, todo endurecimento da vida em certezas consistirá na existência de elos específicos, ações sempre específicas dos mediadores. Isso porque a circulação não provém de um único lugar capaz de comandá-la. 0 que existe é um poder difuso pela rede e, por vezes, acumulado em alguns nós, mas nunca inteiramente fixo. Os ordenamentos podem sair desses mediadores mais ou menos estáveis, mas nunca totalmente preso em uma mesma amarração. Quando tal circulação se dá em forte sincronia, sem maiores contestações ou controvérsias, uma realidade se solidifica um pouco mais e o fato começa a ganhar seus contornos. Cada pessoa, grupo ou objeto que se apropria de tal realidade, seja qual for, agrega maior solidez a mesma. Assim, "(...) a solidez de um fato depende daqueles que o mantém em movimento, tanto humanos quanto não humanos, e formam uma legião de aliados interligados" (NOBRE; PEDRO, 2010, p. 49).

Por outro lado, quando a circulação em sincronia efetuada pelos actantes encontra resistências, obstáculos em sua propagação, tem-se um ambiente de grande turbulência. Entraremos em uma batalha pelos fatos, que possibilita aquilo que Latour denomina por abertura de uma caixa-preta ou caixa-cinza - conceitos considerados quando um componente é apontado como muito complexo. Sempre que formulações passam a ser inquestionáveis, o enunciado ganha solidez de um fato e, dessa forma, a 
caixa-preta começa a ser formada. No embate de argumentos e contra-argumentos, tal caixa-preta se abre em controvérsia e, em meio a tais instabilidades, podemos ver aquilo que Latour denomina como formação de grupos e antigrupos. Assim, grupos se colocam em oposição e, o nascimento e desenvolvimento de uma controvérsia se dão concomitantemente à produção desses grupos em oposição. Quanto maior a discordância, mais profunda ficará a controvérsia, afınal muitos actantes terão de ser utilizados para auxílio nos argumentos usados. Trata-se de um intenso movimento de provas e contraprovas a misturar dinheiro, instituições, pessoas, máquinas, universidades, saberes, enfim, humanos e não humanos com o intuito de que os aliados traiam os argumentos, traiam inclusive o fato (NOBRE; PEDRO, 2010). Em resumo, quando uma caixa-preta é aberta, tem-se a controvérsia.

De modo diverso, o fechamento da caixa-preta seria o fim da turbulência. Assim, se o fechamento da caixa-preta caracteriza o fim da controvérsia, a caixa-cinza significa seu retorno com toda intensidade, pois a "caixa-cinza seria a condição de um artefato que ainda não conseguiu se estabilizar" (NOBRE; PEDRO, 2010, p. 50). Se uma realidade sólida consiste num alinhamento de aliados, em favor de um argumento comum, a controvérsia reaparece toda vez que esses alinhamentos são colocados à contraprova. É necessário atentar para a "extensão da rede que é construída, ou seja, perceber que os actantes são sempre pontualizações de redes bem mais vastas e heterogêneas" (NOBRE; PEDRO, 2010, p. 53).

Pode-se perceber que a análise das controvérsias consiste em um instrumento importante no mapeamento das redes que articulam humanos e não humanos. A controvérsia pode ser entendida como uma disputa em que estão em jogo razões pró ou contra. Para que tais controvérsias aconteçam, faz-se necessária a existência de porta-vozes que construam argumentações que afastem o fato de sua condição de fato em si, para uma condição de algo meramente produzido. De acordo com Nobre e Pedro (2010, p.53), "(...) uma das principais revelações dos estudos de controvérsias é o uso que as partes oponentes fazem de informações e conhecimentos conflitantes". Isso demonstra que os argumentos utilizados dentro do embate da controvérsia acarretam jogos de poder e força, que tem sua expressão na solidez (ou não) que os fatos vão adquirindo. A primeira etapa no processo de entendimento das controvérsias é entender as potências que concebem essas pontualizações e conhecimentos em conflito. Para isso, é necessário manter-se equilibrado, sem pender para um dos lados da controvérsia. Apenas seguir mediadores, descrevendo suas ações.

Nossa proposta metodológica, portanto, apoiada na TAR, objetiva realizar uma análise acerca da batalha pela formatação de ordenamentos, elemento central na teoria. Visa explorar e descrever os processos sempre locais de ordenamento e resistência, analisar e descrever como as caixas-pretas são construídas, encontrando uma porta de entrada na controvérsia. No caso da presente pesquisa, temos a velhice como questão. Propomo-nos adentrar em uma rede de fluxos, rastreando a ação de controvertidos mediadores envolvidos na produção daquilo que entendemos por velhice na atualidade, coletivos a envolver a grande mídia, a mídia acadêmica, hospitais, famílias, tecnologias, o capital, políticas públicas etc. Rastrearemos e seguiremos os desvios produzidos por actantes diversos que, em uma luta de argumentos e contra-argumentos, grupos e antigrupos, produzem a velhice na justa medida de suas traduções. Descrevendo tais ações que os diversos elos da rede produzem, poderemos realizar um rico relato sempre plano da produção da velhice - sem buscarmos uma tridimensionalidade, uma dimensão da realidade entendida como mais profunda.

A condição de caixa-cinza do envelhecimento na atualidade, sua intensa instabilidade, permite o rastreamento de mediações, negociações e articulações de humanos e não humanos, alistando mediadores diversos como aliados de seus argumentos, que acabam por compartilhar um mesmo destino. Todo esse corpo conceitual demanda uma metodologia de pesquisa capaz de cartografar 
tais redes, com seus atores/actantes e respectivas conexões e respectiva dinâmica, isto é, o fluxo das diferentes traduções.

Nesse sentido, cartografias são sempre provisórias, funcionais até o momento em que novas cartografias - portanto, novas paisagens - se imponham. 0 ofício do cartógrafo envolve, assim, uma implicação nas redes que ele cartografa, um entendimento sem exterioridade de seus movimentos e desvios. Para tanto, Ihe é conveniente um equipamento bastante "minimalista" (...) sempre aberto a redefinições (PEDRO, 2008: 11-12).

Similar ao detetive que rastreia caminhos em sua investigação, seguiremos as pistas que despontam, isto é, as mediações que nos demandam desvios no rastreamento de circuitos: "(...) registrar, não filtrar; descrever, não disciplinar" (LATOUR, 2008, p. 86). Observaremos o que os argumentos/ mediações/traduções acerca do envelhecimento produzem por meio de suas ações. Assim como os antigos navegantes, temos um mapeamento sendo delineado no próprio processo do navegar. 0 enveIhecimento se produzindo coletivamente, uma ação em rede. De tradução em tradução, produziremos aquilo que Latour conceitua como um relato. Tal relato deve ser considerado como somente outro mediador, visto que um texto nunca pode ser concebido como representação de uma verdade, sendo sempre um artifício. "Quando o pesquisador se permite escolher os caminhos privilegiados para seguir os atores e o faz conscientemente, produz-se assim uma cartografia que diz respeito a uma situação específica, a um momento específico, segundo determinado pesquisador." (CASTRO, 2008: 61).

Assim, almejamos realizar uma cartografia em meio ao rastreamento da rede de fluxos, delineando uma controvertida produção coletiva do envelhecimento na atualidade. A concepção de redes pede uma metodologia que traga a possibilidade de trabalhar entre a solidez e os fluxos, ou seja, na construção e desconstrução de caixas-pretas. Salienta-se que a TAR "(...) não procura 'ler' ou 'decodificar' as novas mediações de forma igual e comum, pois, agindo assim, estaria fazendo delas apenas um exemplo das forças já estabilizadas" (NOBRE; PEDRO, 2010, p. 55). Busca-se rastrear relações e padrões, registrando os vínculos entre marcos de referência, de forma variável e não estável, ao invés de manter o marco de forma sólida e fixa. Rastreia-se descrevendo e traduzindo, focando no trabalho dos mediadores, em uma dimensão plana, sem profundidade, apenas mapeando o terreno ruidoso dos deslocamentos. Dessa forma, ao buscar traçar o trabalho dos mediadores no coletivo produtor do envelhecimento, apostamos na possibilidade de permitir o surgimento de argumentos diversos, múltiplas traduções, dando voz a diferentes actantes que se espalham pela rede pesquisada.

\section{CONTROVÉRSIAS ACERCA DO ENVELHECIMENTO}

No sentido de iniciar um rastreamento das controvérsias acerca do envelhecimento, elegeu-se a grande mídia como porta de entrada nesses circuitos turbulentos, visto que parece possuir significativa ação impactante e amplificadora de conflitos. Nesse sentido, encontrou-se uma matéria, na revista Veja (2016), denominada "Envelhecer no Século XXI", afırmando que, no fim do século XVI, a velhice era considerada como algo inusitado, vista com entusiasmo e sinal de progresso e avanço. A longevidade era tão singular que as pessoas, querendo parecer mais velhas, mentiam a idade. A idade traduz-se como algo extraordinário (VEJA, 2016). Porém a mesma matéria apresenta que, com o avanço da medicina, da infraestrutura e da nutrição, esse quadro mudou: a população quer parecer jovem. Veja (2016) parece argumentar que envelhecer não é doença e que continua sendo sinônimo de progresso.

Na mesma reportagem, é apontado que o Brasil tem chances de ser, em breve, o país com o maior número de idosos no mundo e que tem como dever buscar atender ao desejo deles de viverem com independência e autonomia. Procura mostrar como as estruturas etárias têm mudado o baixo índice de natalidade e as famílias com números de filhos reduzidos, além de apontar um problema grave: idosos do futuro terão de encarar a longevidade sozinhos, reafirmando a necessidade de autonomia 
e independência. Temos aqui a tradução de um envelhecimento bastante problemático, no Brasil, um idoso desejante por autonomia e independência diante de um país que não o potencializa. Uma série de reportagens realizadas pelo Jornal Hoje e publicadas no site G1 (2016) argumenta como seria a vida de idosos no Brasil e no mundo: "ser humano nunca viveu tanto e esse momento, inédito na história da humanidade, traz muitas dúvidas e novos problemas. Um idoso pode trabalhar? E morar sozinho? É seguro? Esse é o tema da série que o Jornal Hoje exibe em quatro reportagens." (G1, 2016).

O tema velhice é apresentado como algo muito novo no Brasil, uma maior visibilidade e preocupação do poder público/sociedade, derivada de um aumento na expectativa de vida dos indivíduos. Os vídeos das séries mostram idosos enfrentando a solidão, o trabalho mesmo depois de aposentado, limitações físicas etc. "O idoso tem (...) limitações orgânicas, físicas, cansaço que se manifesta antes que uma pessoa adulta. Não se pode exigir que o idoso tenha a mesma carga horária e produtividade que outra pessoa em condição física melhor." (G1, 2016).

Há no terceiro vídeo da série de reportagens, argumentações bem explícitas acerca das limitações de idosos, que afetam a vida deles. São apresentados como pessoas mais frágeis por conta de uma saúde fragilizada. A matéria argumenta por um problema: o idoso deseja ser independente, porém não consegue se cuidar sozinho. A resolução para tal impasse parece ser traduzida como sendo uma articulação entre cuidados e independência na terceira idade. A reportagem mostra que uma saída é contratar cuidadores ou incluir os idosos em organizações que funcionam como uma creche para a terceira idade que tem se tornado cada vez mais comum nas grandes cidades. "O vovô e a vovó chegam no início da manhã e só voltam para casa no fim do dia" (Jornal Hoje, 2016).

Um fator relevante na produção do envelhecimento na atualidade parece ser a estrutura familiar e o número de pessoas dentro dessa família. Veja (2016) afirma que o mantra da velhice no século XXI é envelhecer no lugar, possibilitando que o velho possa permanecer pelo maior tempo possível em casa, sem a necessidade de um familiar por perto todo o tempo. Isso acaba dando autonomia e independência aos idosos que preferem morar sozinhos. A revista apresenta Atul Gawande, professor de medicina e saúde pública da Universidade Harvard, que enfatiza em seu livro intitulado Mortais: "a modernização não rebaixou a posição dos mais velhos. Rebaixou a posição da família. A veneração aos idosos desapareceu, mas não foi substituída pela veneração aos jovens. Foi substituída pela veneração à independência."

Em sintonia com Gawande:

Antigamente as famílias eram grandes. Todo mundo morava perto e as mulheres não trabalhavam, numa fase da
vida cuidavam dos filhos, na outra, dos pais, dos tios, sogros. Mas essa realidade mudou. Hoje, mais de quatro
milhões de brasileiros idosos moram sozinhos. [...] Os velhinhos não querem ficar com ninguém e também não
querem ninguém com eles. Os filhos nessas horas ficam divididos. O que é melhor, respeitar os pais e fazer a
vontade deles ou pensar em primeiro lugar na segurança e forçar o idoso a fazer o que ele não quer? (G1, 2016).

0 argumento aponta que a autonomia do idoso é negligenciada variadas vezes pelos próprios filhos que passam a cuidar dos pais. O velho seria tratado como criança, como se não pudesse fazer escolhas. A ideia aqui é de defesa de uma autonomia do idoso como necessária até mesmo para sua saúde, a produção de um sentimento de protagonismo em sua própria história, adultos, apesar de idosos.

Às vezes a família, com o intuito de ajudar bastante, acaba querendo tomar as decisões que o idoso tomaria, decide pelo idoso. A melhor coisa que a gente pode fazer é perguntar para o idoso 'o que você prefere fazer? '- Não é pelo dinheiro. É pelo simples prazer de me sentir viva, bem e que posso interagir com outras pessoas mais novas do que eu' - Eterna Aparecida, 72 anos $(\mathrm{G} 1,2016)$. 
Temos aqui a defesa de uma valorização das escolhas do idoso em conjunto com uma sensibilidade, quanto à importância do cuidado:

O idoso às vezes tem as preferências dele e de qualquer maneira a qualidade de vida emocional deve ser sempre considerada. Todo mundo que vai envelhecendo, um dia começa a ter limitações. Muitas vezes físicas, muitas vezes, mentais. [...] Os cinco sentidos são prejudicados [...] A saída muitas vezes é contratar um cuidador $(\mathrm{G} 1,2016)$.

A revista Veja procura articular uma população que, como um todo, teria demonstrado desejo de independência com o surgimento da opção de condomínios residenciais pensados para a terceira idade.

Perfeita tradução desses novos tempos, e já bastante difundidos em países desenvolvidos, são os condomínios residenciais pensados exclusivamente para a terceira idade. [...] Nele, o morador terá à disposição serviços que o ajudam a manter sua autonomia ao mesmo tempo que reduzem o risco de acidentes, especialmente as quedas, que são uma das principais causas de morte nas faixas etárias acima de 60 anos. (VEJA, 2016)

Tais condomínios são trazidos pela revista como distantes da realidade de idosos, que não podem arcar com esses custos de residências de alto padrão. Sendo assim, Veja argumenta pela possibilidade de uma oferta de treinamento a trabalhadores comuns, capacitando-os para desempenharem papéis de cuidadores que possam preservar a independência do idoso. Complementar a tal argumento, a revista aborda que, em algumas cidades do Brasil, o Estado/Prefeitura mantém "creches" e locais de moradia para idosos sem nenhum custo.

Uma alternativa para as famílias que não querem se afastar dos idosos, mas também não tem disponibilidade para cuidar deles durante todo o dia, está se tornando cada vez mais comum nas grandes cidades. Funciona como uma creche. O vovô e a vovó chegam no início da manhã e só voltam para casa no fim do dia. [...] A Dona Maria do Céu vai para a creche de idosos em Fortaleza para não ficar sozinha em casa. [...] Além do corre corre do dia a dia, quando o idoso fica em casa, seria necessário contratar uma pessoa e a mão de obra está muito difícil porque tem que ser uma pessoa qualificada, etc. Aqui eles tem integração, socialização...(fala de uma funcionária da "creche"). (JORNAL HOJE, 2016)

Salienta-se que o termo creche parece realizar uma tradução do idoso como infantilizado, tratando-o como crianças. Além disso, a matéria dá forte ênfase na apresentação dos idosos nessas "creches" como estando sempre animados e com energia, dando à velhice um toque de juventude.

Sintonizada com tal abordagem, em outra reportagem chamada "Visão Positiva da velhice meIhora a saúde dos idosos", a revista Veja (2012) traz um estudo, afirmando que idosos que encaram a terceira idade como algo natural possuem menos problemas ao realizarem tarefas no cotidiano. Afirma que atitudes como essa podem levar o idoso a uma maior independência e a resgatar tarefas que antes não conseguia realizar sozinho.

A pesquisa mostra, segundo os pesquisadores, que o ponto de vista de uma pessoa em relação à velhice pode fazer com que ela seja um idoso mais independente e saudável. Eles acreditam que os próximos estudos devam buscar formas de promover o otimismo entre pessoas que estão entrando na terceira idade (VEJA, 2012).

Parece haver, atualmente, uma forte tendência de exaltação à busca de bem-estar, felicidade, saúde e uma vida perfeita. De acordo com Muniz (2014), em matéria do site Extra, especialistas afirmam que "cuidar não só do corpo, mas também da mente, e procurar acompanhar o mundo moderno parece ser a chave para a felicidade na terceira idade". A reportagem continua descrevendo a fala de Duarte, médico do Centro de Medicina Nuclear da Guanabara e mestre em saúde pública: "o idoso tem que se atualizar, seja em relação à música, tecnologia ou política. Quem não se integra aos avanços se sente isolado, o que gera um estado de não adaptação que pode ser confundido com depressão." (MUNIZ, 2014).

A reportagem se utiliza de estudos científicos para afirmar a ideia de que o idoso precisa acompanhar o "ritmo moderno". O velho é traduzido como alguém distante da realidade que, para estar em 
convívio sadio com a sociedade, deve se atualizar, aprendendo o que as outras pessoas sabem ou consomem todos os dias.

O isolamento, inclusive, causa queda no sistema imunológico, o que facilita a aquisição de doenças e dificulta a recuperação de cirurgias. De acordo com a cardiologista e geriatra Elizabete Viana de Freitas, manter-se atuante na sociedade - por exemplo, exercitando o direito do voto - é essencial para evitar isso. (MUNIZ, 2014)

A matéria parece argumentar que os fatores determinantes do isolamento e das suas consequências nocivas à saúde seriam do próprio idoso, trazendo certa dose de culpabilização. Ainda assim, no fim da reportagem parece haver uma ligeira preocupação em se falar sobre um impacto do social na produção da velhice. É trazida a importância de se cultivar, já na criança, um pensamento positivo sobre a velhice, reforçando a ideia de que o sentimento do idoso como estando à margem do social poderia ser alterado com a mudança das pessoas ao seu redor e do seu próprio processo educacional.

Uma reportagem do Globo Repórter (2012), denominada "Conheça os segredos de brasileiros que conquistaram uma velhice feliz e saudável" (2012), parece sintonizada com a matéria anterior, quando destaca idosos que escolheram um estilo de vida mais saudável e superaram suas expectativas. "Imagine percorrer correndo sem parar uma distância de 42 quilômetros e 145 metros. Parece difícil não é? Quase impossível para muitos [..]. Não para este jovem senhor de 83 anos" (GLOBO REPORTER, 2012). 0 termo "jovem senhor" parece argumentar que tais feitos seriam algo de jovens, porém disponíveis à escolha de pessoas idosas. Mais ainda:

uma árvore estava velha, doente e foi cortada, mas a força da vida estava lá e era tão poderosa que a fez brotar
de novo. Assim como essa árvore há idosos que parecem enganar o tempo, os preconceitos e limitações, e a
ciência está interessadíssima neles.[...] 'A gente precisa dar trabalho para a mente', contou dona Maria. 'Este tipo
de desafio de que você pode melhorar, e às vezes nem aceitar a idade que tem é o que a dona Maria, em especial,
se sentir jovem. Ela se desafia toda hora', disse Ana Beatriz. (GLOBO REPORTER, 2012)

Colocações como "jovem senhor" e "às vezes nem aceitar a idade que tem [...] é o que faz a dona Maria, em especial, se sentir jovem" parecem trazer uma exaltação da juventude e negação da idade. Na mesma reportagem, do Globo Repórter, a seguinte fala é demonstrada:

\begin{abstract}
Quem quer viver muito não pode ter preguiça. O dia está amanhecendo e o professor Edgar já está na pista de atletismo se preparando para chegar cada vez mais longe. É difícil dizer uma idade ao certo funcional. Mas a gente pode dizer que ele [Edgar] não está na faixa dos 80 pelos exames clínicos laboratoriais, e a nossa conversa. Está numa faixa mais jovem. "Talvez 70, quem sabe menos", explicou Ana Beatriz. Com acompanhamento profissional como o do professor Edgar e de dona Maira é possível melhorar uma coisinha aqui, outra ali. Um exemplo são os cuidados com a alimentação à medida que a idade avança. Uma das dicas é sobre a importância do consumo de proteínas como carne e ovos para fortalecer os músculos. $E$ ficar muito atento às mudanças do paladar (GLOBO REPÓRTER, 2012).
\end{abstract}

Temos aqui uma articulação de vitalidade, força e independência do idoso com uma busca de práticas esportivas, acompanhamento profissional e boa alimentação.

\begin{abstract}
Pesquisadoras da Universidade do Estado de Santa Catarina acompanharam o dia a dia de 30 moradores de Florianópolis, todos centenários e quanta surpresa. $80 \%$ deles levam a vida com boa dose de independência. São pessoas que mantém uma rotina ativa. [...] Taí um dos segredos da longevidade. 'É ter uma vida independente, uma vida ativa sempre, nem que seja dentro da sua própria rotina, dentro do seu próprio lar', explicou a pesquisadora da UDESC Márcia Zanon Benetti. [...] Encarar a vida com otimismo é o melhor combustível para ultrapassar com saúde os 100 anos de idade. Esse foi o resultado da pesquisa. 'Com o bom humor as pessoas aceitam melhor este processo do envelhecimento, elas se relacionam muito melhor com a família com os cuidadores e elas se movimentam melhor', afirmou a pesquisadora Márcia. 'Viver bem, nisso os centenários parecem mestres. 'Falte o que faltar, eu sou contente, sou alegre, pra mim tudo dez', afirmou dona Inácia (GLOBO REPÓRTER, 2012).
\end{abstract}

Articulando o argumento com pesquisa científica, temos, além do idoso esportista e independente, o idoso otimista, isto é, a produção do otimismo como modo de melhoria da saúde. Consequentemente, teríamos uma parcela de responsabilidade das pessoas em relação ao que serão na velhice. Uma vida 
ativa, independente e cheia de otimismo seria um dos segredos da longevidade. A matéria parece, assim, fazer uso de ligeira culpabilização dos idosos pelos seus males ao não buscarem tais caminhos.

\title{
Sintonizado com tais argumentos, uma reportagem do Globo Esporte afirma que
}

\begin{abstract}
é aconselhado a manter-se sempre em movimento. Na terceira idade, dores articulares e degenerativas aumentam e ocorre a redução da capacidade funcional, por isso é importante manter a independência e prevenir a incapacidade, reabilitando esses pacientes e garantindo qualidade de vida. A atividade esportiva ajuda a prevenir e melhorar as condições físicas e mentais do paciente geriátrico, desde que bem orientado e medicado (quando necessário). Muitos adultos com idades entre 65 anos ou mais, gastam em média, 10 horas ou mais por dia sentado ou deitado, tornando-os o grupo etário mais sedentário. Eles estão pagando um alto preço por sua inatividade, com maiores taxas de quedas, obesidade, doenças cardíacas. (SIMÕES, 2015)
\end{abstract}

Mais uma vez, o esporte é trazido como possiblidade de enfrentamento de uma velhice inativa e dependente. 0 cotidiano é chamado a argumentar por um idoso sedentário e doente, visto que muitos deles ficariam a maior parte do tempo sentados ou deitados. Porém, mesmo sendo algo do cotidiano, a matéria parece trazer certa dose de culpabilização dos idosos com a expressão "pagando um alto preço por sua inatividade". Priscila Marques e Sergio Antonio Carlos, respectivamente, mestre em Psicologia e doutor em Serviço Social, apontam que

assim, a grande disseminação do uso da teoria da atividade parece estar criando uma cultura da atividade, estimulando a crença de que as pessoas de mais idade são as principais responsáveis pela condução adequada do próprio envelhecimento, o que Guita Debert (1999) denomina a "reprivatização da velhice". Para atingir esse objetivo basta que o idoso adote uma série de medidas, como, por exemplo, exercícios físicos regulares, alimentação balanceada, controle das emoções negativas, entre outras. A difusão desta crença acaba embasando e estimulando a máxima altamente difundida em nossa sociedade de "só é velho quem quer". Cria-se, desse modo, a representação de que a velhice bem-sucedida está ao alcance de todos, bastando, para isso, adotar um estilo de vida e consumo apropriados. Esse cenário acaba gerando uma culpabilização dos idosos, que não conseguem assim se reconhecer. Portanto, segundo o discurso, principalmente de geriatras e gerontólogos, o fato de um velho se encontrar abandonado e dependente é decorrência de uma espécie de "negligência auto-infringida." (MARQUES; CARLOS, 2006, p. 63)

A revista Veja, através da reportagem "uma nova vida na velhice" (2015), parece dar ênfase à indústria da saúde, em articulação a um idoso potencial consumidor.

\begin{abstract}
Mas isso não minimiza o desafio aparentemente insolúvel por trás disso: [...] um número cada vez menor de contribuintes para sustentar um número cada vez maior de aposentados. Este desequilíbrio já levou alguns governantes a aumentarem a idade mínima para a aposentadoria e mudarem suas políticas de pensão para adiar ou reduzir benefícios e manter as pessoas na força de trabalho. [...] Para manter as pessoas trabalhando por mais tempo, é crucial mantê-las saudáveis. É por isso que a indústria da saúde deve desempenhar um papel importante, esforçando-se para lidar com os desafios do envelhecimento da população (JIMENEZ, 2015).
\end{abstract}

Temos aqui o crescimento da população velha articulado a desafios que podem afetar os sistemas de saúde, economias e políticas. Além disso, afirma-se que as dificuldades econômicas se devem ao número reduzido de contribuintes na idade ativa de trabalho para auxiliar no sustento do governo. Nesse aspecto, aponta-se como sendo interessante investir em saúde, para que a população seja mais saudável e tenha uma expectativa de vida maior, podendo contribuir por mais tempo.

Em um segundo vídeo do Jornal Hoje, abordado no site do G1, temos a articulação da velhice com o trabalho por meio de dois modos distintos: trabalho como prazer e trabalho como obrigação para complementar a aposentadoria. 
Todo mundo conhece alguém com mais de 60 anos que não quer saber de deixar de trabalhar. [...] Para muitos, esse trabalho é bem mais que uma ocupação, é um prazer. Sr. Joel faz parte desse exército de mão de obra da terceira idade. Começou na roça, foi bombeiro [...], se aposentou e agora é taxista. -- Eu trabalho: Uma porque estou me sentindo bem e outra que eu preciso trabalhar também (Joel, 76 anos). A aposentadoria curta é outro motivo para continuar trabalhando. [...] Com os muitos ajustes na previdência, os salários caíram muito e para muitos aposentados a saída foi arrumar um emprego. A gente pensa sempre em parar, ter mais um sossego, mas fazer o que, a gente tem que trabalhar porque precisa. A aposentadoria é pouquinha, né. Por minha vontade eu pararia, ia passear... (Antônio de Castro, 72 anos)." (G1, 2016).

Em contrapartida a um idoso energizado para o trabalho, Brum (2012), em um artigo na revista Época, valorizando a velhice, afirma que o velho não precisa de eufemismos. Em meio a uma juventude cultuada, haveria uma constante tentativa de tornar os velhos mais jovens, negando a velhice como algo natural e necessário.

Na semana passada, sugeri a uma pessoa próxima que trocasse a palavra "idosas" por "velhas" em um texto. E fui informada de que era impossível, porque as pessoas sobre as quais ela escrevia se recusavam a ser chamadas de "velhas": só aceitavam ser "idosas". Pensei: "roubaram a velhice" (BRUM, 2012).

O autor traz uma argumentação sobre os inúmeros eufemismos utilizados no sentido de desvalorizar a velhice como, por exemplo, utilizar a expressão casa de repouso ao invés de asilo ou substituir velhice por terceira idade.

Tenho muito medo dos eufemismos, porque eles soam bem intencionados. São os bonitinhos, mas ordinários da língua. O que fazem é arrancar o conteúdo das letras que expressam a nossa vida. Justo quando as pessoas têm mais experiências e mais o que dizer, a sociedade tenta confiná-las e esvaziá-las também no idioma. [...] Velho é uma conquista. Idoso é uma rendição (BRUM, 2012).

A juventude é trazida como um valor e não uma fase da vida, isto é, uma negação da experiência dura da morte.

A velhice é o que é. É o que é para cada um, mas é o que é para todos, também. Ser velho é estar perto da morte. E essa é uma experiência dura, duríssima até, mas também profunda. Negá-la é não só inútil como uma escolha que nos rouba alguma coisa de vital (BRUM, 2012).

Outro aspecto importante encontrado seria a velhice em sua articulação com a tecnologia. Uma propaganda do Itaú (DESAFIO DIGITAL APP ITAÚ) em vídeo parece argumentar pela necessidade dos velhos de acompanhar os avanços tecnológicos, se mantendo atualizados. Ao mesmo tempo, ressalta-se uma imagem do idoso engraçado, que não entende muitas coisas e parece uma criança, ao conseguir se utilizar de artefatos da atualidade.

[Duas idosas conversando] 'Eu sou bem antenada. Nós estamos na era digital, né. Tudo tchutchutchu' [a idosa fez um som remetendo a digitação no celular]. 'Nós duas juntas porque assim uma pode ajudar a outra. Então, vamos acessar o whatsapp. Ih, já errei' (ITAÚ, 2016).

Em outra propagando do mesmo banco, temos a tradução do velho como tendo que se adequar ao mundo atual e a forma como os jovens de hoje lidam com isso. Nesse sentido, parece tornar-se uma consequência vê-los como engraçados, por não conseguirem ter a mesma perspicácia e excluí-los, caso a adequação não funcione.

A gente ia para o rolê de olho no crush [risadas]. [Kéfera pergunta] 'Me contem os bafos'. [As idosas respondem] 'Bafos? O que são bafos?' [Mais risadas. Kéfera continua] 'Eu acho que vocês têm que ter um linguajar, umas expressões em que a galera se identifique. [...] Além das expressões, tem os memes. [...] Eu quero que vocês chutem o que é meme'. 'Mesma coisa?' [Uma idosa responde. Todas gargalham. As vovós perguntam à Kéfera] 'O que você já ensinou a sua avó no celular?' [Ela responde] 'A atender e desligar a ligação' (ITAÚ, 2016). 


\section{CONSIDERAÇÕES FINAIS}

Tendo por base o rastreamento das controvérsias acerca do envelhecimento realizado, foram verificados diferentes modos de produção da velhice na atualidade. As fronteiras do envelhecimento entendido como sinal de longevidade e avanço parecem encontrar fortes resistências em sua circulação, por meio de uma corrida incessante contra a velhice.

Dentre as diversas mediações analisadas, temos aquelas que parecem enxergar o velho como limitado, cansado, sem a mesma produtividade esperada dos mais novos, com a saúde fragilizada. Não conseguindo se cuidar sozinho e ser independente, tem como opção cuidadores ou inclusão em organizações que funcionam como creches. Outras argumentações já defendem uma maior autonomia e independência para eles e seus familiares, passando afirmações que apontam que sua autonomia, muitas vezes, é negligenciada pelos próprios familiares com uma falsa ideia de cuidado. A autonomia é traduzida como essencial, para que o idoso se sinta desafiado a realizar suas tarefas do dia a dia e não perca suas capacidades motoras e cognitivas.

Alguns argumentos apontam também que, se por um lado, uma das maneiras de promoção da autonomia seria a adesão às residências para idosos. Outros afirmam que essas residências se assemelham a creches, podendo trazer infantilização. Algumas mediações rastreadas apresentam também o idoso como possuindo uma necessidade de atualização no sentido de se manter inserido no cotidiano. Um idoso necessitado de uma busca incessante por aprender a lidar com novas tecnologias, para se manter em contato com as pessoas das faixas etárias mais jovens.

Outro aspecto relevante encontrado seria a tradução de que idosos, quando encaram a chamada terceira idade como algo natural, possuem menos problemas ao realizarem as tarefas do dia a dia. Uma matéria afirma, ainda, que idoso é um eufemismo usado para se referir ao velho, e que isso pode trazer consequências, como perda de identidade e não aceitação de suas condições atuais, trazendo essa incessante busca por jovializar as pessoas mais velhas. Mais ainda: apontam para uma culpabilização da velhice, por não buscar caminhos que o conduziriam para tal jovialidade e acusam a produção de uma velhice negligente.

Enfım, muitos são os mediadores a fazer circular diversos elementos que constroem o que podemos chamar, hoje, de "velhice". Após rastrearmos mediações como as acadêmicas, da grande mídia impressa, de matérias publicitárias, dentre outras, podemos afirmar que encontramos um coletivo produtor do envelhecimento na atualidade que ainda se apresenta fortemente instável, com características de caixa-cinza. Um idoso que se produz imbricado com o capital e o consumo, com a grande mídia, com a academia, com o esporte, com a medicina, dentre outros. 


\section{REFERÊNCIAS}

ALVES JUNIOR, Edmundo de Drummond (Org.). Envelhecimento e vida saudável. Rio de Janeiro: Apicuri, 2009.

BEAUVOIR, Simone de. A velhice. Tradução de Maria Helena Franco Monteiro. Rio de Janeiro: Nova Fronteira, 1990.

BRUM, Eliane. Me chamem de velha. Época Online. 2012. Disponível em: <http://revistaepoca.globo. com/Sociedade/eliane-brum/noticia/2012/02/me-chamem-de-velha.html>. Acesso em: 13 ago. 2016.

CASTRO, R. B. Redes e Vigilância: Uma experiência de cartografia Psicossocial - estudo de caso no município de Guarujá, São Paulo / BR. Dissertação (Mestrado em Psicossociologia de Comunidades e Ecologia Social) Instituto de Psicologia, Universidade Federal do Rio de Janeiro, 2008.

DEBERT, G. G. A reinvenção da velhice: socialização e processos de reprivatização do envelhecimento. São Paulo: Universidade de São Paulo/Fapesp, 1999.

ESTATUTO DO IDOSO. Lei $\mathbf{n}^{\circ} \mathbf{1 0 . 7 4 1}$, de 1 de outubro de 2003. Dispõe sobre o estatudo do idoso e das outras providências. Brasília: Senado Federal, 2003.

FERREIRA, A. B. H. Miniaurélio século XXI escolar: o minidicionário da Língua portuguesa. Rio de Janeiro: Nova Fronteira, 2000.

GIBSON, H. B. It keeps us young. Ageing and Society, 20 (6), 773-339, 2000.

G1. Série de Reportagens mostra como vivem os idosos no Brasil e no mundo. Disponível em: <http:// g1.globo.com/jornal-hoje/noticia/2016/06/serie-de-reportagens-mostra-como-vivem-os-idosos-nobrasil-e-no-mundo.html>. Acesso em: 13 ago. 2016.

GLOBO REPORTER. Conheça os segredos de brasileiros que conquistaram uma velhice feliz e saudável. 2012. Disponível em: <http://g1.globo.com/globo-reporter/noticia/2012/11/conheca-os-segredos-debrasileiros-que-conquistaram-uma-velhice-feliz-e-saudavel.html>. Acesso em: 04 out. 2016.

GOLDMAN, Sara Nigri. As dimensões culturais, sociais e políticas do envelhecimento. In: ALVES JUNIOR, Edmundo de Drummond (Org.). Envelhecimento e vida saudável. Rio de Janeiro: Apicuri, 2009. p. 27-42.

HADDAD, Eneida Gonçalves de Macedo. A ideologia da velhice. São Paulo: Cortez, 1986.

IBGE. Instituto Brasileiro de Geografia e Estatística. A dinâmica demográfica brasileira e os impactos nas políticas públicas. 2010. Disponível em: <http://www.ibge.gov.br/home/estatistica/populacao/ indicsociosaude/2009/comdin.pdf>. Acesso em: 16 ago. 2016.

ITAÚ. Desafio Digital App Itaú. Disponível em: <https://www.youtube.com/watch?v=0Ycxc8jX|BI>. Acesso em: 13 ago. 2016.

ITAÚ; Gírias da Internet Kéfera e Vovloggers. Disponível em: <https://www.youtube.com/ watch?v=nXeP4liWIUs\&t=149s>. Acesso em: 13 ago. 2016. 
JIMENEZ, Joseph. Uma nova vida na velhice. Revista Veja. 2015. Disponível em: <http://veja.abril.com. br/economia/uma-nova-vida-na-velhice/>. Acesso em: 13 ago. 2016.

JONES, R. L. (2006). 'Older people' talking as if they are not older people: positioning theory as an explanation. Journal of Aging Studies, 20 (1), 79-91.

LATOUR, B. A Esperança de Pandora. Bauru: EDUSC, 2001.

Ciência em ação: como seguir cientistas e engenheiros sociedade afora. São Paulo: Editora UNESP, 2000.

Do humano nas técnicas. In: SCHEPS, R. (Org.) O Império das técnicas. Campinas: Papirus, 1996.

Jamais fomos modernos. São Paulo: Editora 34, 1994.

Reensamblar Lo Social: uma Introdución a la Teoria del Actor-red. Buenos Aires: Manantial, 2008.

MARQUES, P. Z.; CARLOS, S. A. A cultura da atividade e o trabalho com idosos. Revista Brasileira de Ciências do Envelhecimento Humano. 2006. Disponível em: <http://assets.izap.com.br/fapmg.org.br/ uploads/noticias/anexo/Reprivatizacao_da_velhice.pdf> Acesso em: 28 nov. 2016.

MARTINEZ, Terezinha Monteiro; MARQUES, Emilly Pereira; SILVA, Evelyn de Melo. Envelhecimento e cuidado social: um debate necessário. In: ALVES JUNIOR, Edmundo de Drummond (Org.). Envelhecimento e vida saudável. Rio de Janeiro: Apicuri, 2009. p. 103-118.

MUNIZ, Camilla. Campanha defende que preparar-se para velhice é a chave para viver mais. Site Extra. 2014. Disponível em: <http://extra.globo.com/noticias/saude-e-ciencia/campanha-defende-quepreparar-se-para-velhice-a-chave-para-viver-mais-13999126.html> Acesso em: 13 ago. 2016.

NERI, A. L., \& Freire, S. A.(org.). E por falar em boa velhice. Campinas: Papirus, 2000.

NOBRE, J. C. A.; PEDRO, R. M. L. R. Dos sólidos às redes: Algumas questões sobre a produção de conhecimento na atualidade. in Série Documenta/Universidade Federal do Rio de Janeiro. Pós-graduação em Psicossociologia de Comunidades e Ecologia Social, ano III, n 12-13, - p. 43 -56, 2001-2002.

Redes de Bioética e Biotecnologias da Reprodução: Controvérsias teóricas e metodológicas. In RECIIS. Rio de janeiro, vol. 1, n. 2, p. 224-233, 2007.

Reflexões sobre possibilidades metodológicas da Teoria Ator-Rede. Revista Cadernos UniFOA. № 14, p. 47 a 56, dez/2010. Disponível em: <http://www.unifoa.edu.br/cadernos/edicao/14/47.pdf >. Acesso em: 04 jul. 2016.

PACHECO, J. L. Sobre a aposentadoria e envelhecimento. In J. L. Pacheco, J. L. M. Sá, L. Py \& S. N. Goldman (Orgs.). Tempo rio que arrebata (pp.59-73). Holambra: Setembro, 2005.

PAZ, Serafim Fortes (Org.). Envelhecer com cidadania: quem sabe um dia? Rio de Janeiro: ANG - RJ; CBCISS, 2000. 
PEDRO, R. M. L. R. Redes e Controvérsias: ferramentas para uma cartografia da dinâmica psicossocial. In: VII Esocite - Jornadas Latino-Americanas de Estudos Sociais das Ciências e das Tecnologias, Rio de Janeiro, 2008.

SCHNEIDER, R. H; IRIGARAY, T. Q. 0 envelhecimento na atualidade: aspectos cronológicos, biológicos, psicológicos e sociais. Estudos de Psicologia. Campinas, 2008, 25(4), p. 585-593.

SIMÕES, Júlio Assis. A maior categoria do país: o aposentado como ator político. In: BARROS, Myriam Moraes Lins de (orgs.). Velhice ou terceira idade? Rio de Janeiro: Fundação Getúlio Vargas. 1998. p. 13-34.

SIMÕES, Ana Paula. Velhice x Sedentarismo: a importância da prática de atividade física por idosos. Globo Esporte. 2015. Disponível em: <http://globoesporte.globo.com/eu-atleta/saude/noticia/2015/08/ velhice-x-sedentarismo-importancia-da-pratica-de-atividade-fisica-por-idosos.html $>$. Acesso em: 04 out. 2016.

VEJA. Visão Positiva da velhice melhora a saúde dos idosos. Revista Veja. 2012. Disponível em: <http:// veja.abril.com.br/saude/visao-positiva-da-velhice-melhora-a-saude-de-idosos/>. Acesso em: 13 ago. 2016.

VEJA. Envelhecer no Século XXI. Revista Veja. 2016. Disponível em: < http://veja.abril.com.br/brasil/ envelhecer-no-seculo-xxi/>. Acesso em: 13 ago. 2016. 